\title{
Prinsip Dasar Berwirausaha dan Cara Peminjaman Modal Usaha dari Perbankan Untuk UMKM Pada Wirausaha Pelajar Indonesia Cabang Bogor
}

\author{
1*Widhi Wicaksono, ${ }^{2}$ Suyatin, ${ }^{3}$ Rachmawaty, ${ }^{4}$ Eko Cahyadi, ${ }^{5}$ Panji Galih Kusumi Adie \\ Universitas Pamulang, Tangerang Selatan, Banten, Indonesia \\ *dosen01049@unpam.ac.id
}

\section{Abstrak}

Sudah seharusnya seluruh elemen masyarakat termasuk dosen dapat ikut serta mewujudkan generasi muda yang mampu mendirikan usaha yang unggul di era Globalisasi dan berperan dalam kemajuan bangsa dan negara. Oleh karena itu, kita perlu mempersiapkan remaja sebagai generasi muda yang berkompeten dan mempunyai daya saing tinggi di masyarakat untuk menjadi seorang wirausahawan yang tidak hanya dapat mengurangi jumlah pengangguran tetapi juga secara jangka panjang dapat berkontribusi terhadap pembangunan perekonomian nasional. Remaja sebagai Generasi muda saat ini lebih banyak yang menginginkan mendapatkan pekerjaan dibandingkan berwirausaha, seperti dalam Data BPS Kota Bogor, mengenai data Penduduk yang bekerja pada umur 15 Tahun Ke Atas, menurut kelompok umur dan jenis kelamin di kota Tangerang Selatan, diperolah data pada kelompok umur 25-54 lebih banyak penduduk yang bekerja sebanyak 495.539 penduduk dibandingkan kelompok umur lainnya. Dari data tersebut di atas, sudah seharusnya seluruh elemen masyarakat termasuk dosen dapat ikut serta mewujudkan generasi muda yang mampu mendirikan usaha yang unggul di era Globalisasi dan berperan dalam kemajuan bangsa dan negara. Pihak Mitra yaitu Wirausaha Pelajar Indonesia cabang Bogor diberikan pendampingan agar mereka dapat mengetahui urutan dalam peminjaman modal dari syarat syarat administrasi, kelayakan usaha, serta kelayakan mitra sehingg mitra mendapatkan permodalan dengan harapan bisa memajukan usahanya sampai berkembang

Kata Kunci: Wirausaha Pelajar Indonesia, Generasi Muda, Akses Perbankan, Wirausaha

\begin{abstract}
All elements of society, including lecturers, should be able to participate in creating a young generation that is able to establish a superior business in the era of globalization and play a role in the progress of the nation and state. Therefore, we need to prepare youth as a young generation who are competent and highly competitive in society to become entrepreneurs who can not only reduce the number of unemployed but also in the long term can contribute to the development of the national economy. Teenagers as the currentyounger generation are more likely to want to get a job than entrepreneurship, as in Bogor City BPS data, regarding population data working at the age of 15 years and over, by age group and gender in the city of South Tangerang, data obtained by age group 25-54 more people who work as many as 495,539 residents than other age groups. From the data above, all elements of society, including lecturers, should be able to participate in creating a young generation who is able to establish a superior business in the era of globalization and play a role in the progress of the nation and state. Partners, namely Indonesian Student Entrepreneurs in the Bogor branch, are given assistance so that they can find out the order in borrowing capital from the administrative requirements, business feasibility, and partner eligibility so that partners get capital in the hope of advancing their business until it develops
\end{abstract}

Keywords: Indonesian Student Entrepreneurs, Young Generation, Access to Banking, Entrepreneurs

\section{PENDAHULUAN}

Mahasiswa adalah tulang punggung majunya Negara baik secara akademis dan ide-ide pembaharuan yang ilmiah. Namun para mahasiswa perlu juga menjadi sarana incubator lahirnya wirausaha wirausaha muda kreatif dan berakhlak terutama Wirausaha Pelajar Indonesia cabang Bogor yang sudah memberikan waktunya dan memberikan wadah bagi mahasiswa yang juga menjadi wirausaha. Seluruh elemen masyarakat harus mampu menciptakan generasi muda 
berkarakter santun, cerdas dan mandiri melalui wirausaha. Untuk menciptakan generasi muda berkarakter dan mandiri, seluruh Kampus di Indonesia perlu meningkatkan kesadaran akan pentingnya berwirausaha dan mengubah pola fikir yang biasanya lulus melamar kerja, menjadi lulu sudah menjadi wirausaha mandiri dan sukses.

Remaja merupakan generasi muda yang dapat menghadirkan perubahan bangsa, negara ke arah yang lebih baik. Saat seorang remaja dapat memanfaatkan waktunya dengan baik dan memiliki ide dalam mendirikan usaha, maka mereka akan lebih termotivasi untuk mengembangkannya. Karena remaja merupakan generasi muda harapan bangsa yang harus berperan lebih dalam mengembangkan usaha di tengah-tengah masyarakat, jangan sampai perusahaan besar yang dikelola oleh pihak asing yang terus mendominasi sehingga akan membuat masyarakat menengah ke bawah semakin tidak dapat mendirikan usaha.

Namun generasi muda saat ini lebih banyak yang menginginkan mendapatkan pekerjaan dibandingkan berwirausaha, seperti dalam Data BPS Kota Bogor, mengenai data Penduduk yang bekerja pada umur 15 Tahun Ke Atas, menurut kelompok umur dan jenis kelamin di kota Bogor Selatan, diperolah data pada kelompok umur 25-54 lebih banyak penduduk yang bekerja sebanyak 495.539 penduduk dibandingkan kelompok umur 15-24 sebanyak 96.482 penduduk dan 55 tahun ke atas sebanyak 68.224 penduduk.

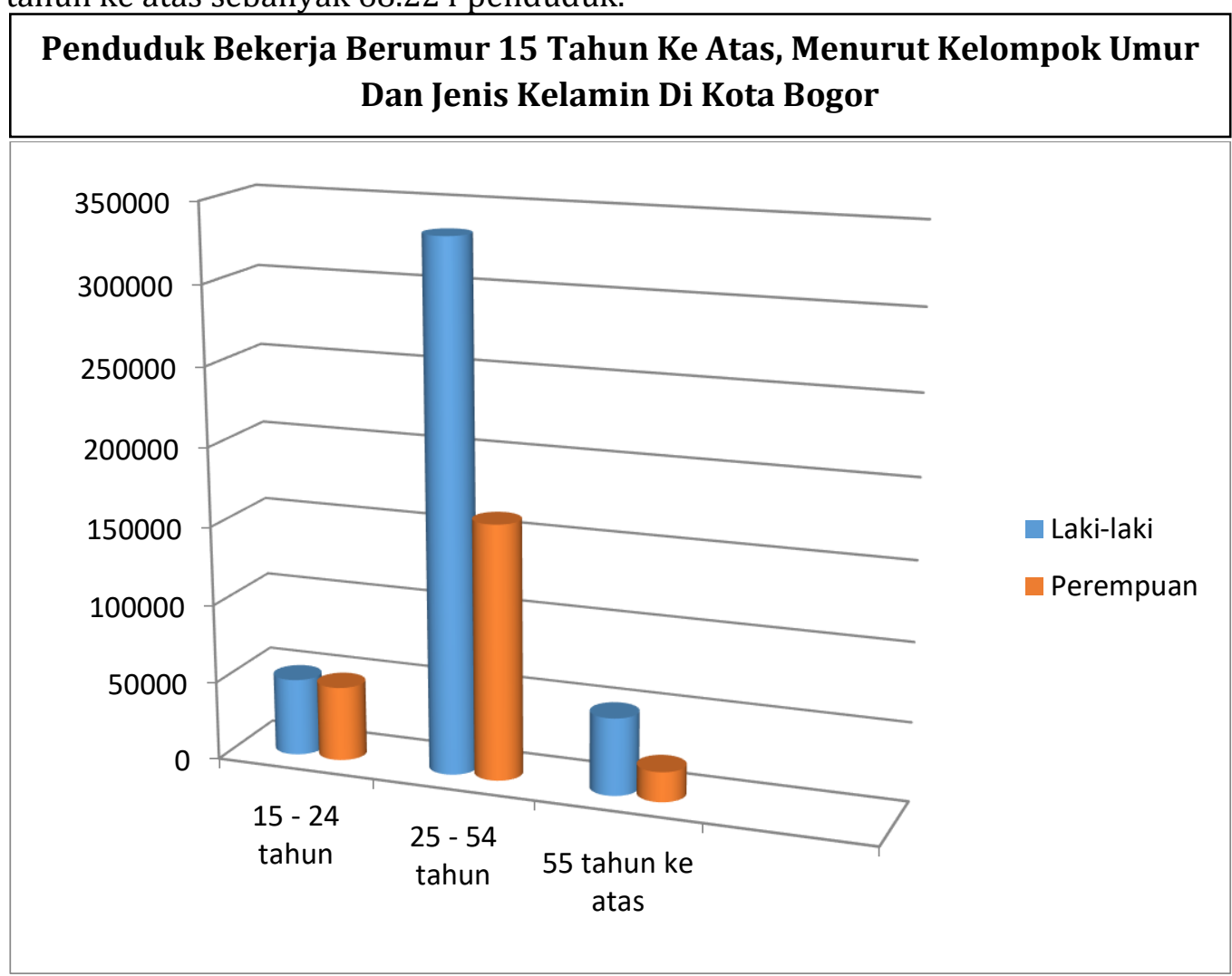

Gambar 1. Sumber: BPS (Badan Pusat Statistik) Kota Bogor 2018

Menurut data BPS Kota Bogor pada Jenis Industri UMKM dan industri besar, industri makanan dan minuman masih mendominasi dengan sejumlah 335 industri dan kemudian industri pakaian jadi, konveksi dan penjahit dengan 263 industri, karena sektor ini yang paling diminati oleh para pedagang dalam menjual karena termasuk jenis usaha yang selalu dibutuhkan masyarakat yaitu masuk dalam kategori sandang, pangan dan papan. 


\section{Jumlah Industri Umkm, Industri Mikro, Kecil Dan Menengah Di Kota Bogor}

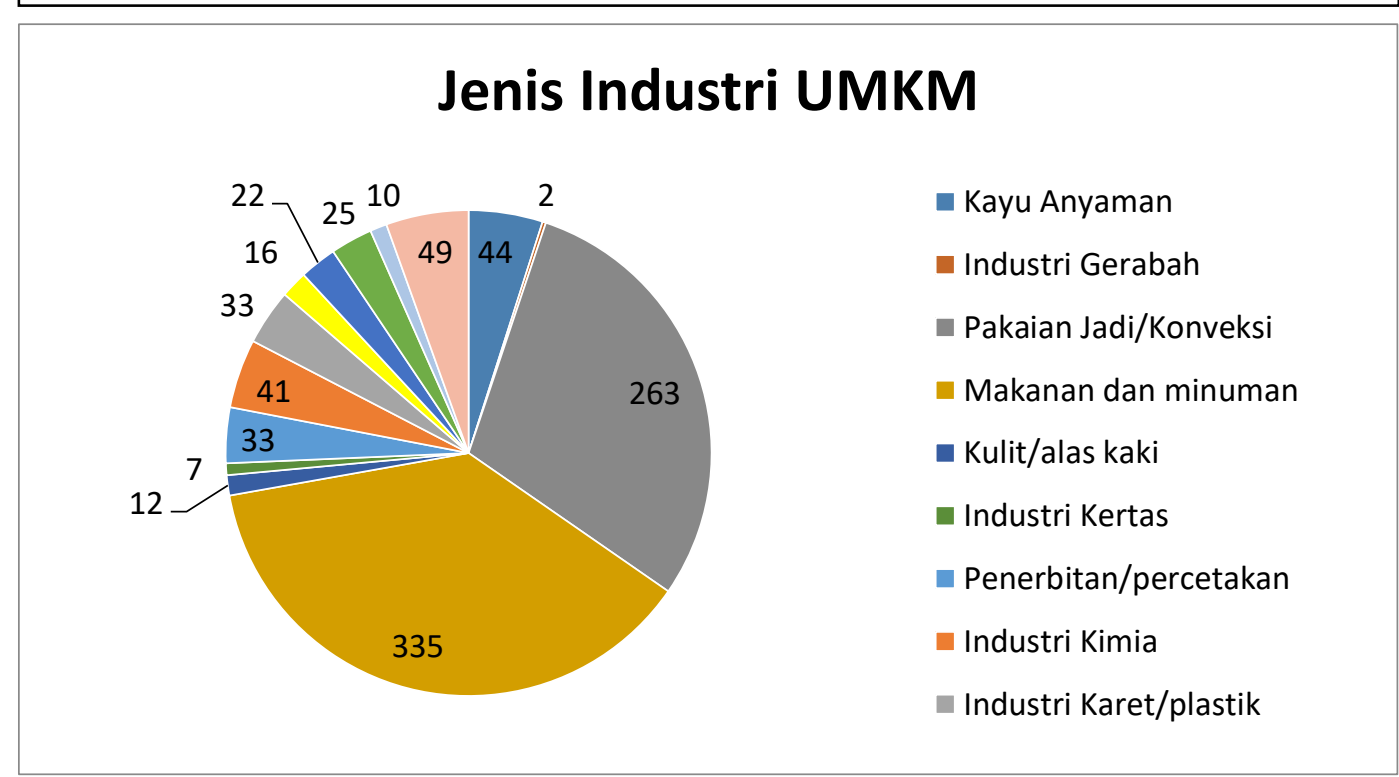

Ganbar 2. Sumber: BPS (Badan Pusat Statistik) Kota Bogor 2018

Dari data tersebut di atas, Usaha Mikro, Kecil dan Menengah (UMKM) lebih didominasi usaha makanan, minuman dan pakaian, itu artinya generasi muda perlu membuat inovasi produk, kreatif produk dan diferensiasi produk yaitu mempunyai ciri khas produk agar dikenal oleh masyarakat dari segi produk makanan, minuman dan pakaian.

Seluruh elemen masyarakat dan berbagai kalangan harusnya terus memotivasi para generasi muda untuk dapat berwirausaha, jangan sampai generasi muda kita hanya ingin bekerja dan tidak mau menjadi wirausaha. Dari penelitian yang dilakukan kepada mahasiswa Universitas Trunojoyo, yaitu A.A. Vilathuvahna dan Nugroho (2015), Melakukan penelitian terhadap mahasiswa di Universitas Trunojoyo, di antara hasil penelitiannya ialah "Ditemukan bahwa hanya $17 \%$ mahasiswa memiliki keinginan untuk menjadi wirausahawan setelah lulus, lainnya $(83 \%$ mahasiswa) berkeinginan untuk menjadi PNS, dosen, jurnalis dan bekerja di tempat lain."

Dari penelitian tersebut, harusnya menjadi intropeksi dari berbagai pihak untuk ikut serta memberikan motivasi dan kelimuan terkait kewirausahaan termasuk dari kalangan dosen untuk berperan mengadakan penyuluhan, workshop ataupun pelatihan kepada generasi bangsa yaitu para Wirausaha Pelajar Indonesia cabang Bogoragar termotivasi menjadi seorang wirausaha

Oleh karena itu, generasi muda harus dibuat terobosan dan kita perlu mempersiapkan remaja sebagai generasi muda yang berkompeten dan mempunyai daya saing tinggi di masyarakat dalam mempersiapkan siswa agar mereka pihak mitra yaitu Wirausaha Pelajar Indonesia cabang Bogordapat menjadi seorang wirausahawan (entrepreneur) yang tidak hanya dapat mengurangi jumlah pengangguran tetapi juga secara jangka panjang dapat berkontribusi terhadap pembangunan perekonomian nasional. Salah satu upaya tersebut dengan membekali dan memberikan pemahaman mengenai sikap kewirausahaan (entrepreneurship) melalui penyuluhan dan workshop.

Dalam pengabdian kepada masyarakat (PKM) yang dilakukan oleh dosen-dosen UNPAM khsusnya dosen Manajemen Fakultas Ekonomi ini salah satu upaya dalam membekali dan memberikan ilmu pengetahuan dan keterampilan wirausaha kepada Wirausaha Pelajar Indonesia cabang Bogor dengan tema, "Prinsip Dasar Berwirausaha dan Cara Peminjaman Modal Usaha dari perbankan untuk UMKM pada Wirausaha Pelajar Indonesia cabang Bogor Timur Kota Bogor".

\section{METODE}

Metode pendekatan yang digunakan dalam kegiatan PKM ini adalah sebagai berikut. Saat permulaan dalam pelaksanaa kegiatan, dimulai dengan ice breaking dan brain gym agar peserta PKM dapat lebih termotivasi mengikuti penyuluhan yang diberikan oleh dosen-dosen Fakultas 
Ekonomi Universitas Pamulang. Sambutan sebagai pembuka dari rangkaian acara oleh Ketua Pelaksana PKM dosen Fakultas Ekonomi Universitas Pamulang dan dari pihak wirausaha pemula yang terdiri dari pelajar dan mahasiswa yaitu Founder WPI Bogor dan Pembina Wirausaha Pelajar Indonesia (WPI) Pusat serta dilanjutkan dengan pembacaan doa sebelum memulai kegiatan agar seluruh rangkaian kegiatan dapat berjalan lancar.

Penyajian materi kegiatan Pemberian Materi PKM dengan tema "Meningkatkan Daya Jual Produk melalui Pemasaran Online di Masa Pandemi pada WPI (Wirausaha Pelajar Indonesia) Wilayah Bogor". Adapun Prof. Dr. S. Nasution (2015:26) berpendapat mengenai "Ciri-ciri Belajar yang ditinjau berdasarkan sumber yaitu diantaranya memanfaatkan sepenuhnya segala sumber informasi sebagai sumber bagi pelajaran termasuk alat-alat audio-visual dan memberi kesempatan untuk merencanakan kegiatan belajar dengan mempertimbangkan sumber-sumber yang tersedia." Dalam pemberian materi kewirausahaan menggunakan video conference berupa Aplikasi Zoom.

Dalam pemberian materi PKM oleh dosen-dosen menggunakan alat bantu berupa aplikasi zoom dikarenakan masih dalam masa pandemi Covid 19, seperti gambar di bawah ini:

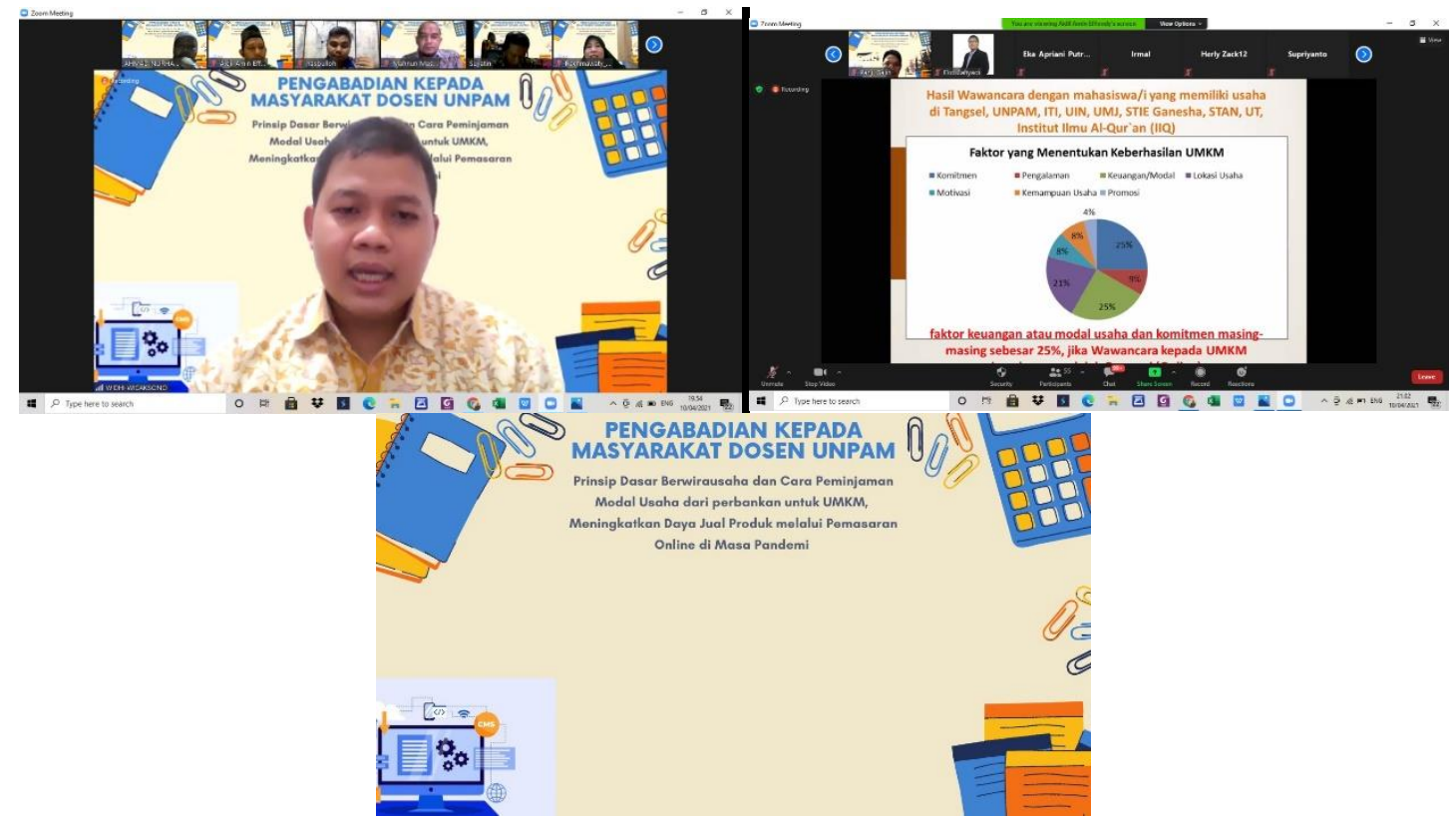

Gambar 3. Tim PKM Dosen Universitas Pamulang sedang memberikan materi

Selain pemberian materi PKM oleh tim PKM Dosen, terdapat juga sambutan dari Mitra PKM yaitu Bapak H. Hasbulloh, S.E., MA.Ek. sebagai Founder WPI Kota Bogor yang memberikan motivasi kepada wirausaha muda agar dapat berjuang mengembangkan usahanya. Tim PKM Dosen juga mengadakan ice breaking sebelum pemberian materi PKM agar peserta lebih fokus dalam mengikuti penyuluhan yang dilakukan dosen-dosen Fakultas Ekonomi Universitas Pamulang, seperti pada gambar berikut:

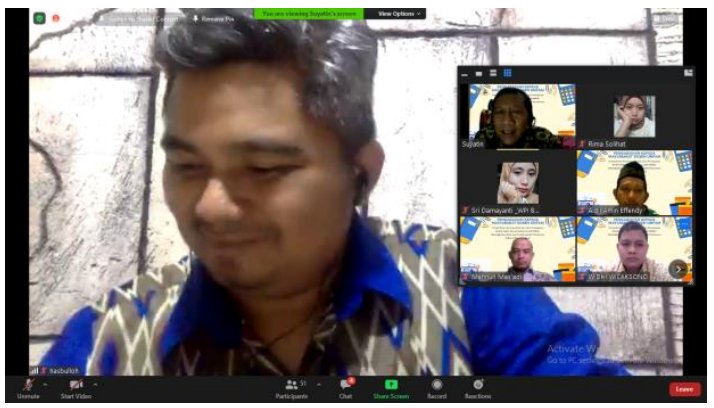

Gambar 4. Sambutan dari Mitra PKM 


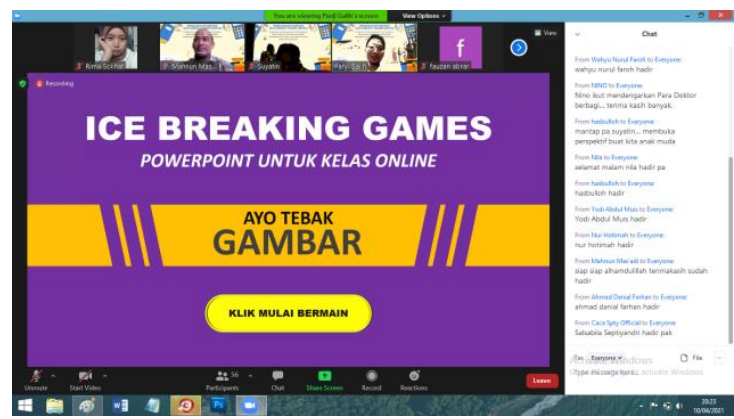

Gambar 5. Ice Breaking oleh Tim PKM

\section{HASIL DAN PEMBAHASAN}

Hasil dari pemberian materi wawasan wirausaha yang kreatif, inovatif dan diferensiatif oleh dosen Manajemen Universitas Pamulang dan simulasi dan pendampingan bagi mitra WPI untuk akses modal kepada lembaga keuangan dan perbankan. agar mereka dapat mengetahui urutan dalam peminjaman modal dari syarat syarat administrasi, kelayakan usaha, serta kelayakan mitra sehingg mitra mendapatkan permodalan dengan harapan bisa memajukan usahanya sampai berkembang.

Permasalahan yang dihadapi oleh para pengusaha UKM WPI Bogor Bogor ialah Kurangnya Ilmu pengetahuan dalam wirausaha Wirausaha Pelajar Indonesia cabang Bogor belum memiliki ilmu pengetahuan dan wawasan yang memadai mengenai wirausaha yang kreatif, inovatif dan diferensiatif dan Tidak adanya akses dalam permodalan perbankan.

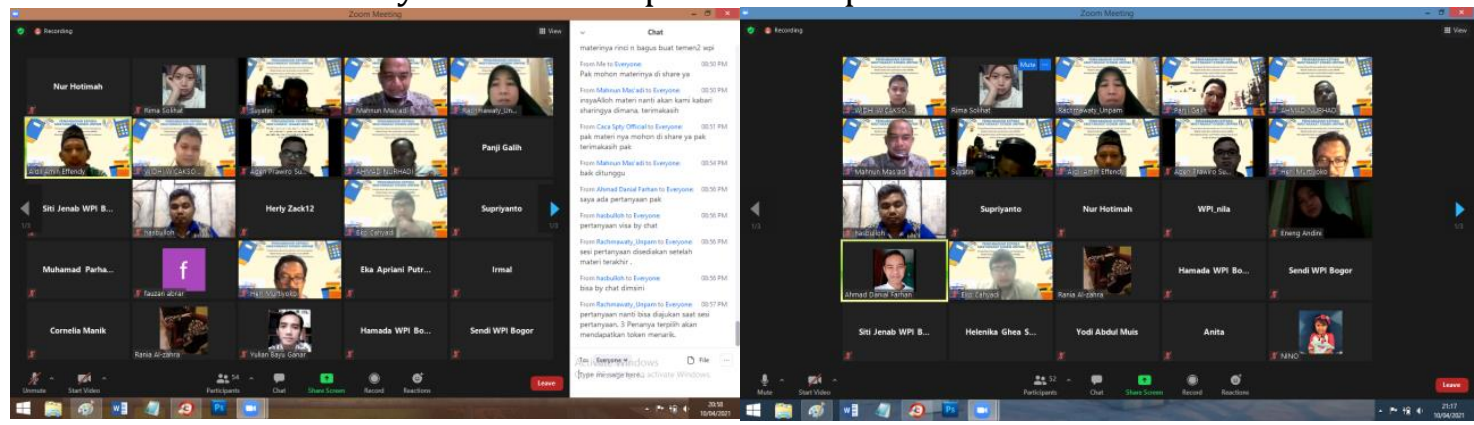

Gambar 6. Sesi Diskusi dan Tanya Jawab bersama WPI Kota Bogor

Adapun gambar di atas yaitu diskusi dan tanya jawab antara peserta kepada Tim PKM, kemudian Tim PKM yang merupakan dosen-dosen Unpam menanggapi dan menjawab pertanyaan yang diajukan oleh para peserta dan memberikan hadiah kepada para peserta yang bertanya dan berhasil menjawab pertanyaan dari Tim PKM Dosen.

\section{KESIMPULAN}

Hasil dari Pelaksanaan kegiatan PKM oleh dosen-dosen Fakultas Ekonomi Universitas Pamulang dapat membuahkan hasil yang positif terlihat dari antusias dan bersemangat dalam mengikuti pemberian materi, tanya jawab dan kuis.

Saran kami bagi pelaku UKM WPI Bogor untuk dapat bertambahnya keilmuan pelaku UKM WPI Bogor dalam menjadikan usahanya lebih kreatif, inovatif dan diferensiatif, dan mendapatkan akses mudah dalam permodalan baik kepada lembaga keuangan maupun perbankan. Kami berharap kegiatan pengabdian kepada masyarakat di masa yang akan datang dapat lebih terprogram dan terlaksana dengan baik. Semoga kegiatan pengabdian masyarakat ini dapat bermanfaat bagi masyarakat, khususnya WPI BogorHasil dari Pelaksanaan kegiatan PKM oleh dosen-dosen Fakultas Ekonomi Universitas Pamulang dapat membuahkan hasil yang positif terlihat dari antusias dan bersemangat dalam mengikuti pemberian materi, tanya jawab dan kuis.

Saran kami bagi WPI (Wirausaha Pelajar Indonesia) Kota Bogor untuk dapat secara konsisten menerapkan pemasaran melalui media sosial agar dapat meningkatkan penjualan di saat pandemi pada masa ini. 
Kami berharap kegiatan pengabdian kepada masyarakat di masa yang akan datang dapat lebih terprogram dan terlaksana dengan baik. Semoga kegiatan pengabdian masyarakat ini dapat bermanfaat bagi masyarakat, khususnya WPI (Wirausaha Pelajar Indonesia) Kota Bogor.

\section{DAFTAR PUSTAKA}

Ajimat, A., et al. (2020). Berwirausaha Memanfaatkan Media Sosial Pada Daerah Sepatan. ADI Pengabdian Kepada Masyarakat, 1(1), 69-76.

Anugrah, R. J. (2020). "Efektifitas Penerapan Strategi Online Marketing oleh UMKM dalam Masa Pembatasan Sosial Berskala Besar (PSBB) Corona Viruses Disease 2019 (Covid-19)." MANOVA (Jurnal Manajemen dan Inovasi), 2(2).

BPS (Badan Pusat Statistik) Kota Bogor. 2020. https://bogorkota.bps.go.id/publication.html, diakses pada 29 Maret 2021

Budiyanto, A., \& Effendy, A. A. (2020). Analisa Kebijakan Pemerintah Kota Tangerang Selatan terhadap Pemberdayaan Koperasi dan UMKM dan Dampaknya terhadap Pemerataan Kesejahteraan Masyarakat. Jurnal Mandiri: Ilmu Pengetahuan, Seni, Dan Teknologi, 4(1), 8093.

Djamarah, Syaiful Bahri dan Aswan Zain. 2014. Strategi Belajar Mengaja. Cet 5, PT Rineka Cipta, Jakarta. Hlm. 39-41

Effendy, A. A., \& Sunarsi, D. (2020). Persepsi Mahasiswa Terhadap Kemampuan Dalam Mendirikan UMKM Dan Efektivitas Promosi Melalui Online Di Kota Tangerang Selatan. Jurnal Ilmiah MEA (Manajemen, Ekonomi, \& Akuntansi), 4(3), 702-714.

Effendy, A. A., Budiyanto, A., Nurhadi, A., Murtiyoko, H., \& Mas'adi, M. (2020). "Implementasi Kewirausahaan dan Koperasi di Sekolah pada SMK Mulia Buana, Parung Panjang-Kab. Bogor." DEDIKASI PKM, 1(2), 105-110.

Fadly, H. D., \& Sutama, S. (2020). “Membangun Pemasaran Online Dan Digital Branding Ditengah Pandemi Covid-19." Jurnal Ecoment Global: Kajian Bisnis dan Manajemen, 5(2), 213-222.

Hamalik, Oemar. 2008. Kurikulum dan Pembelajaran, Cet. 7, PT. Bumi Aksara, Jakarta. Hlm. 37

Mas'adi, M., Effendy, A. A., Nurhadi, A., Wicaksono, W., \& Murtiyoko, H. (2021). Berwirausaha Dengan Semangat Kolaborasi Bersama Kurir Online Pada Pelaku UMKM Di Wilayah Reni Jaya Pamulang Barat. Jurnal Pengabdian Dharma Laksana, 3(2), 173-178.

Nasution, Prof. Dr. S., 2015. "Berbagai Pendekatan dalam Proses Belajar dan Mengajar", PT Bumi Aksara, Jakarta

Rahayu, R., \& Day, J. (2015). Determinant Factors of E-commerce Adoption by SMEs in Developing Country: Evidence from Indonesia. Procedia-Social and Behavioral Sciences, 195, 142-150.

Sunarsi, D. (2018). Analisis Motivasi Kerja Tenaga Pendidik Sukarela Pada Pusat Kegiatan Belajar Masyarakat (PKBM) Bimasda Kota Tangerang Selatan. Kreatif: Jurnal Ilmiah Prodi Manajemen Universitas Pamulang, 6(2), 53-65. 